\title{
APRESENTAÇÃO DO DOSSIÊ SOCIOLOGIA POLÍTICA: CENÁRIOS TEÓRICOS E PERSPECTIVAS EMPÍRICAS
}

\author{
Organizadores: \\ Antonio Teixeira de Barros ${ }^{1}$ \\ Edson Terra Azevedo Filho ${ }^{2}$ \\ Fabrício Barbosa Maciel $^{3}$ \\ Hugo Borsani ${ }^{4}$ \\ Julian Borba ${ }^{5}$
}

A política sempre foi uma questão relevante para os estudos sociológicos, desde os fundadores do campo das ciências sociais até a atualidade. Com o passar do tempo e o processo crescente de diferenciação e autonomização de cada disciplina das ciências sociais, a ciência política tornou-se predominante nos estudos do sistema político. Isso, contudo, não reduziu a relevância da sociologia política (CODATO; LEITE, 2014). O que houve, na realidade, foi uma redefinição de especificidades de agendas de pesquisa. Enquanto a ciência política prioriza temas como eleições, partidos políticos, organização e estrutura dos parlamentos e dos demais poderes, a sociologia política, a partir da análise da relação entre indivíduo e sociedade, estuda temas como: cultura política, comportamento político, participação política, desigualdades sociais, movimentos sociais, direitos humanos, minorias e grupos minorizados, racismo, políticas de identidade e reconhecimento, cidadania, entre outros.

A tematização das questões políticas sob a ótica da sociologia política tem como

\footnotetext{
${ }^{1}$ Doutor em Sociologia pela Universidade de Brasília (1999). Docente e pesquisador do Programa de Pós-Graduação do Centro de Formação da Câmara dos Deputados. Editor da revista E-Legis.

E-mail: antonibarros@gmail.com

${ }^{2}$ Doutor em Sociologia Política pela Universidade Estadual do Norte Fluminense (UENF). Professor Associado na UENF do Laboratório de Engenharia de Produção (LEPROD). Diretor Financeiro da incubadora TecCampos na gestão 2016-2019. Áreas de interesse: empreendedorismo, gestão e prospectiva estratégica, desenvolvimento regional e inovação tecnológica. E-mail: edsonterrafilho@ gmail.com

${ }^{3}$ Doutor em Ciências Sociais pela Universidade Federal de Juiz de Fora (UFJF), com estadia de sanduíche na PH Freiburg, Alemanha. Pós-Doutorado em Sociologia na Universidade Humboldt, de Berlim, Alemanha. Professor adjunto, área de atuação "teoria sociológica", do Departamento de Ciências Sociais de Campos, no Instituto de Ciências da Sociedade e Desenvolvimento Regional, da Universidade Federal Fluminense (UFF). Coordenador do NUESDE: Núcleo de novos estudos sobre desigualdade social. Co-coordenador do GT "Reconhecimento, justiça e desigualdade", no Congresso da SBS de 2017. Bolsista de produtividade em pesquisa do Conselho Nacional de Desenvolvimento Científico e Tecnológico (CNPq). E-mail: macielfabricio@ gmail.com

${ }^{4}$ Doutor em Ciência Política pelo Instituto Universitário de Pesquisas do Rio de Janeiro (IUPERJ). Docente e pesquisador do Laboratório de Estudos da Sociedade Civil e do Estado (LESCE) e do Programa de Pós-Graduação em Sociologia Política (PPGSP), na Universidade Estadual do Norte Fluminense Darcy Ribeiro (UENF) - E-mail: hugobor1@gmail.com

5 Doutor em Ciência Política pela Universidade Federal do Rio Grande do Sul (UFRGS) Sócio da Associação Brasileira de Ciência Política. Vice-Coordenador do Programa de Pós-Graduação em Sociologia Política da Universidade Federal de Santa Catarina (UFSC). Pesquisador do CNPq. Coordenador do Projeto "Mudanças e permanências nos padrões de participação política no Brasil (1988-2013) (PROCADCAPES) www.participacaopolitica.cfh.ufsc.br. E-mail: borbajulian@yahoo.com.br
} 
característica distintiva a análise dessas questões do ponto de vista de sua relação com os fatores sociais e contextuais. Em suma, o enfoque da sociologia política "alia o estudo das instituições com o das formas pelas quais os grupos sociais tentam fazer valer seus interesses no âmbito estatal" (ABRÚCIO, 1998, p.195-196). Para o autor, enquanto as análises da ciência política tornam-se cada vez mais formalistas, a sociologia política "tem de trazer um 'sangue novo' ao debate sobre as instituições. Não basta mostrar como elas funcionam; é preciso mostrar quem se beneficia com isso e quão democráticos são os processos decisórios” (p.198). Em outras palavras, como explica Nash (2010), a sociologia política é o ramo da sociologia que se concentra nas reflexões sobre o poder, o Estado e o dever político, mas sempre considerando as bases sociais substantivas e normativas da política.

Convém ressaltar o legado da sociologia política para a constituição de disciplinas de grande relevância para os estudos políticos, tais como a sociologia dos partidos políticos, a sociologia das elites, a sociologia dos movimentos sociais, a sociologia da juventude e a sociologia ambiental, entre outros temas. Por outro lado, devemos considerar que as questões políticas são estudadas pela sociologia de forma difusa e diluída, ou seja, nem sempre as linhas de pesquisa ou os programas de pós-graduação apresentam claramente a denominação de sociologia política. Isso envolve também questões de poder e tomada de decisões dentro do campo. Isso explica a existência de mais de 30 programas de pós-graduação em ciência política e apenas quatro especificamente em sociologia política no Brasil atualmente. ${ }^{6}$

Outro dado que deve ser ressaltado é que as ciências sociais brasileiras, em seu seu conjunto, tiveram como berço a Escola de Sociologia Paulista, de orientação europeia, focada em métodos qualitativos. Foi na Universidade de São Paulo (USP) que nasceu a sociologia política brasileira (SALLUM JÚNIOR, 2002), com a contribuição de cientistas sociais estrangeiros que lecionaram na USP e dos nativos formados por eles. No primeiro caso destacam-se Roger Bastide e Claude Levi-Strauss. No segundo caso destaca-se a contribuição de Florestan Fernandes e seus assistentes, como Fernando Henrique Cardoso, Octávio Ianni e outros. Esse grupo, ora em colaboração, ora em competição, voltou-se para o estudo do poder do Estado na conformação da ordem capitalista, do sistema industrial e como agente do desenvolvimento nacional.

A sociologia política que se desenvolveu sob a influência desse grupo voltou-se principalmente para o estudo do poder político do Estado na conformação das classes sociais, das relações de trabalho, do sistema industrial, da urbanização e demais formas de desenvolvimento. Trata-se de uma abordagem que considerava as variáveis endógenas e exógenas do desenvolvimento e do subdesenvolvimento, incluindo a dependência em relação

\footnotetext{
${ }^{6}$ Os programas de pós-graduação em sociologia política são das seguintes instituições: Universidade Federal de Santa Catarina (UFSC), Instituto de Estudos Sociais e Políticos/Universidade do Estado do Rio de Janeiro (IESP/UERJ), Universidade Estadual do Norte Fluminense (UENF), Universidade de Vila Velha (UVV).
} 
aos países em nível mais avançado.

Em resumo, a sociologia política analisa as questões políticas a partir de suas conexões com a sociedade e o contexto sócio-histórico. Isso significa que a sociologia política "não se caracteriza por qualquer tema específico, sendo seus pesquisadores voltados para o estudo de diferentes assuntos a partir do espírito analítico da referida abordagem" (PERISSINOTTO; CODATO, 2018, p.24). Isso porque nas palavras dos autores, a sociologia política "não é uma teoria nem um método específico", mas uma abordagem, "isto é, um espírito analítico que pretende lançar olhar atento às conexões entre a esfera da política e a esfera do social” (p.51).

Conforme aponta Sallum Júnior (2002) foi dessa forma de se fazer sociologia política que nasceria a nova disciplina denominada ciência política, voltada principalmente para a análise institucional das questões e temas políticos. Para o autor, "a obsessão pela análise endógena das instituições políticas, embora tenha produzido conhecimentos inestimáveis, faz perder de vista as articulações entre política e sociedade" (p.86). Em sua avaliação, cabe à sociologia política, portanto, introduzir "sistematicamente as dimensões institucionais e simbólicas na reconstrução das relações de dominação e das lutas políticas” (p.86).

Em seu recente processo de autoafirmação acadêmica, a ciência política seguiu outro rumo, voltando-se para os padrões estadunidenses, como está registrado nas principais obras de referência sobre a história da disciplina no Brasil. ${ }^{7}$ Essa trilha diferenciada se deve a um conjunto de fatores conjunturais e institucionais, destacando-se a interlocução de um grupo de pesquisadores de Minas Gerais com pesquisadores estadunidenses na década de 1960, com o apoio financeiro da Fundação Ford. Outro impulso foi a reforma universitária de 1968, com a instituição de um sistema nacional de pós-graduação. O terceiro fator nesse processo é de ordem geracional, com a emergência de uma geração de pesquisadores mineiros mais interessados no estudo empírico das questões políticas em contraposição à tradição ensaísta da sociologia paulista. Esse contexto é resumido da seguinte forma:

o processo de construção da ciência política como disciplina autônoma está situado em um contexto mais abrangente ligado a transformações que alteraram o perfil organizacional da prática acadêmica no Brasil. O estilo de trabalho introduzido pelos cientistas políticos relacionava-se com as iniciativas de difusão de um novo ideal de profissionalismo que foi moldado a partir da confluência entre dois fatores: os influxos da Fundação Ford e a criação de um sistema nacional de pós-graduação, previsto pela reforma universitária, de 1968, como parte do projeto concebido pelo regime militar de "modernização" do sistema universitário e científico. Escoradas numa espécie de elogio à profissionalização, as "novas disciplinas" - a ciência política e a antropologia - fincariam sua presença no sistema acadêmico brasileiro, equilibrando o jogo de forças que até então era amplamente favorável à sociologia. Trata-se de um momento de transição geracional intrínseco à estrutura dos processos de desenvolvimento das ciências sociais, em que as clivagens entre gerações respondem a desacordos que apontam para sentidos conflitantes acerca do grau de especialização e de engajamento

\footnotetext{
${ }^{7}$ A bibliografia é extensa, mas citaremos alguns títulos, como: Lamounier, 1982; Reis, 1993; Quirino, 1994; Forjaz, 1997; Arruda, 2001; Limongi, 2001; Keinert e Silva, 2010; Lessa, 2010.
} 
público do intelectual (KEINERT e SILVA, 2010, p.95).

A situação política do Brasil, inaugurada com o regime militar foi um fator que se impôs aos emergentes estudos sobre política, abrindo duas linhas de análise. A primeira, de orientação sociológica, tinha como foco "compreender as razões ligadas à emergência do autoritarismo", enquanto a segunda procurava "delinear uma plataforma política que pudesse orientar a recomposição do regime democrático no Brasil" (KEINERT e SILVA, 2010, p. 79). As duas linhas convergiam para a possibilidade de construir "uma modalidade própria de intervenção política combinava-se à invocação de novos parâmetros de cientificidade, vistos como traço distintivo de um perfil de trabalho que se apoiava num ideal renovado de profissionalismo" (KEINERT e SILVA, 2010, p. 80).

Renato Lessa (2006, p.22) traça um paralelo entre a realidade estadunidense e a brasileira, no que se refere às práticas de pesquisas empiricamente orientadas no campo da ciência política. Nos Estados Unidos, segundo sua análise, "tratava-se de estudar - e promover a democracia como objeto realmente existente, e não como fabulação". No caso brasileiro, "uma ciência política, configurada pelos valores de uma ciência positiva e empírica, tratou de investigar não a democracia, mas o 'autoritarismo' e a vislumbrar as formas de sua superação". Em razão disso, "pode-se falar de um cientificismo a meias, posto que normativamente orientado pela desejabilidade da democracia". Nas palavras do autor:

Entre nós, uma teoria empírica da democracia exigia uma teoria empírica da
ausência de democracia. É evidente que tal passagem exige operadores de
ordem normativa, que valorizam de modo positivo a democracia, ainda que a
descrevam mais como conjunto de procedimentos do que como
materialização de valores e crenças (Lessa, 2006, p.22).

A adoção da nomenclatura "ciência política" para denominar a disciplina emergente "é um dos sinais mais expressivos da lógica que redefiniu os traços identitários de uma área de estudos, cuja designação mais habitual era dada até então pelo termo 'Política'". Além disso, a adoção de técnicas quantitativas nos estudos, "aparecia como símbolo maior de um empreendimento cujo sentido de inovação se apoiava num diagnóstico acerca do que seriam as fragilidades metodológicas da ciência social praticada no Brasil até a primeira metade da década de 1960” (KEINERT e SILVA, 2010, p. 80).

A adesão aos modelos científicos da ciência política praticada nos Estados Unidos é justificada como uma guinada em termos de profissionalismo disciplinar, sustentado em quatro pilares: (a) alinhamento ao modelo das hard sciences; (b) compromisso com a objetividade científica; (c) confiança nos poderes da análise científica formal; (d) aversão aos padrões ideológicos do ensaísmo e todas as demais ameaças à "pureza disciplinar" (LESSA, 2006, p.18).

O processo de institucionalização da ciência política no Brasil envolveu, portanto, um 
expresso afastamento da sociologia, a fim de afirmar sua identidade. ${ }^{8}$ Essa postura foi emblemática em dois grupos de pesquisadores. O primeiro sediado no Departamento de Ciência Política da Universidade Federal de Minas Gerais (UFMG), enquanto o segundo foi reunido pelo Instituto Universitário de Pesquisas do Rio de Janeiro (Iuperj). É oportuno ressaltar que essas duas instituições implantaram os programas pioneiros de pós-graduação na área de ciência política. Ambos "constituem o núcleo central de institucionalização da disciplina no Brasil". Foram os cientistas políticos "vinculados a essas instituições que assumiram a liderança desse processo" (FORJAZ, 1997, sem paginação). Do ponto de vista metodológico, ainda conforme a mesma autora,

a análise da obra desse grupo permite perceber a diversidade e o pluralismo. Os mineiros e cariocas não têm um paradigma teórico comum e não constituem uma escola de pensamento no sentido estrito do termo. Mas, são todos críticos do marxismo dominante nas ciências sociais brasileiras nos anos 60 e 70. Sem ser empiristas, ou funcionalistas, como frequentemente são caracterizados, eles se notabilizam pela preocupação em coletar evidências empíricas e históricas que suportem a explicação científica (FORJAZ, 1997, sem paginação).

Pensar na institucionalização ${ }^{9}$ e na autonomização ${ }^{10}$ da disciplina ciência política implica considerar suas subdivisões e disputas internas, ou seja, compreendê-la como uma “disciplina dividida e plural” (LESSA, 2006, p.20), ou seja, com múltiplas abordagens metodológicas e perspectivas teóricas. O processo de autonomização disciplinar passa necessariamente por uma modalidade de autonomização cultural, ou seja, pautada em valores acadêmicos e profissionais, teorias mais específicas sobre política e métodos próprios. A institucionalização por sua vez, "envolve um conflito mais ou menos declarado entre distintas visões de ciência política" (LEITE, 2010, p.151). Assim, institucionalização, profissionalização e grau de autonomia estão estreitamente articulados. Afinal, institucionalização e profissionalização "são necessárias para que o campo da ciência política seja relativamente autônomo em relação a outros campos, em especial o campo político, aos outros campos acadêmicos e ao campo intelectual" (LEITE, 2010, p.152).

Um dos elementos importantes no processo de institucionalização e autonomia de um campo acadêmico são as publicações científicas, que produzem "um ritualismo intelectual e procedimental que, por efeito da concorrência, estandardiza a produção de artigos científicos".

\footnotetext{
${ }^{8}$ A respeito da tendência de distanciamento da disciplina em relação às demais ciências sociais, Feres Júnior (2000, p.108), adverte que "como mostra o exemplo americano, a separação da Ciência Política em especialidades isoladas em si mesmas, e das Ciências Sociais como um todo, contribui para o esvaziamento crítico do debate político e acadêmico".

${ }^{9}$ Institucionalização é entendida como "o processo de estabelecimento de regularidades sociais, isto é, procedimentos tácitos ou explícitos (codificados) que orientam a ação dos indivíduos, tais como regras, normas e valores sociais" (LEITE, 2010, p.152).

${ }^{10}$ Autonomização constitui "o processo de institucionalização, adicionado das características da especificidade e irredutibilidade: instituições que passam progressivamente a obedecer a uma lógica específica. E outras palavras, que passam, progressivamente, a 'refratar', 'reprocessar' constrangimentos, influências ou estímulos de campos externos" (LEITE, 2010, p.152).
} 
Essa padronização "manifesta-se na homogeneização da estrutura, do tipo de escrita, da metodologia ou dos temas escolhidos". Assim, o número de publicações e de citações "funciona como um instrumento transmissor de distinção do pesquisador" (HARO, 2017, p.95-96).

Nesse quesito é importante ressaltar as interfaces entre os periódicos das duas áreas atualmente. Levantamentos recentes mostram que as revistas de sociologia publicam grande parte dos estudos produzidos pelos cientistas políticos e vice-versa (BARROS; SILVA, 2018a; 2018b). Um exemplo é a Revista Brasileira de Ciência Política, cujo conteúdo publicado é de cerca de 40\% de sociologia política (BARROS; SILVA, 2018b).

Foi nesse contexto reflexivo que a revista E-Legis se propôs a produzir um dossiê temático contemplando as principais abordagens da sociologia política brasileira na atualidade. Intitulado Sociologia política: cenários teóricos e perspectivas empíricas, o dossiê contou com a colaboração na organização de pesquisadores que representam os principais programas de pós-graduação em sociologia política em âmbito nacional. Além disso, como resultado de chamada pública e de rigoroso processo de revisão cega por pares, o produto final conta com um conjunto de sete artigos selecionados. O que caracteriza o dossiê é a pluralidade temática e a diversidade de abordagens, uma das características da sociologia política brasileira, conforme já foi ressaltado acima. Afinal, estudar questões políticas sob a ótica da sociologia requer um apurado exercício de imaginação sociológica.

$\mathrm{O}$ artigo que abre o dossiê tem como título Cultura política e a ênfase na escolha: a teoria evolutiva da emancipação humana, de Lucas Toshiaki Archangelo Okado e Ednaldo Aparecido Ribeiro. A partir do trabalho de Ronald Inglehart sobre a emergência dos valores pós-materialistas na cultura política, os autores apresentam alguns elementos recentes deste debate, focando principalmente na teoria evolutiva da emancipação humana e nas críticas a essa abordagem.

Ainda na trilha da cultura política, o artigo de Marcello Baquero, Ana Julia Bonzanini Bernardi e Jennifer Azambuja de Morais, trata dos Padrões emergentes de uma cultura política juvenil no sul do Brasil. O texto examina os diferentes processos de socialização política que ao longo da juventude influenciam a forma como o jovem vê o processo democrático e as possibilidades de construir uma outra cultura política juvenil assertiva. A hipótese é de que há uma reprodução de padrões de comportamento político tradicionais entre os jovens.

Priscila Ramos Reis assina o texto seguinte, intitulado Esfera pública virtual e redes sociais: um estudo das interações entre usuários e a página do Planalto no Facebook. O estudo analisa as formas como os usuários do Facebook utilizaram o espaço virtual durante o debate sobre o impeachment da ex-presidente Dilma Rousseff, transformando-o num espaço público de discussão de demandas particulares e coletivas. 
Estatismo entre elites legislativas federais brasileiras, de autoria de Ednaldo Aparecido Ribeiro, Anderson de Oliveira Alarcon e Éder Rodrigo Gimenes, partindo da abordagem culturalista, examina como os parlamentares da $54^{\circ}$ legislatura do Legislativo federal brasileiro se posicionam acerca do papel do Estado no desenvolvimento geral da nação. O objetivo foi identificar como os parlamentares de legendas partidárias localizadas à esquerda e à direita do espectro ideológico se diferenciam em seus posicionamentos sobre estatismo.

Luana Puppin Pratti colabora com Deputados do Espírito Santo: perfil sócio-econômico e trajetória política, 1987-2011. O estudo identifica o perfil social dos parlamentares, no qual se destacam elevada predominância masculina, alta escolaridade, presença acentuada de empresários e profissionais liberais, em especial advogados. Em relação ao perfil político notase um crescente acúmulo de experiência do parlamentar médio, supostamente incompatível com os baixos níveis de organização interna e institucionalização da casa legislativa estadual do Espírito Santo.

$\mathrm{Na}$ sequência, o artigo Interfaces das interfaces socioestatais: um estudo sobre as ouvidorias, de Lígia Helena Hahn Lüchmann, Rachel Abrão e Matheus Kieling, aborda as ouvidorias públicas como mecanismos de interface socioestatal no interior da estrutura administrativa do Estado. Em termos empíricos, são examinados o funcionamento desses mecanismos tanto no âmbito da esfera municipal (Prefeitura Municipal de Florianópolis), como estadual (Governo do Estado de Santa Catarina).

Fechando o dossiê temos a contribuição de Fabiana Gomes Rodrigues, Hugo Borsani Borsani e Nelson Luís Motta Goulart Os rumos da judicialização da política de medicamentos. $\mathrm{O}$ artigo analisa os desafios e impasses da política pública de medicamentos diante das intervenções do Poder Judiciário. A pesquisa ressalta ações estratégicas direcionadas a garantir o acesso dos indivíduos a medicamentos, e, ao mesmo tempo, garantir a permanência da política pública de medicamentos desenvolvida pelo estado. As conclusões mostram que a intervenção do Judiciário promove uma alternativa possível e eficaz para aqueles que buscam o fornecimento gratuito de medicamentos. No entanto, as determinações judiciais provocam efeitos, como o aumento da demanda de judicialização.

\section{Referências}

ABRUCIO, Fernando Luiz. Por uma sociologia política da burocracia. Novos Estudos CEBRAP, n.52, p. 195-199.

ARRUDA, Maria Arminda do Nascimento. (2001), "A modernidade possível: cientistas e ciências sociais em Minas Gerais". In: MICELI, Sergio (org.). História das ciências sociais no Brasil. São Paulo, Sumaré, vol. 1.

BARROS, Antonio T.; Lucas Emanoel Silva. O Poder Legislativo como objeto de estudo da Ciência Política no Brasil: análise da produção acadêmica em periódicos qualificados. Revista Brasileira de Ciência Política, 2018a (no prelo).

BARROS, Antonio T.; Lucas Emanoel Silva. A mídia como objeto de estudo da ciência política 
brasileira: análise da produção em periódicos qualificados. Teoria \& Sociedade, 2018b (no prelo)

CODATO, Adriano N.; LEITE, Fernando. Por que precisamos de uma Sociologia Política? In: Sessão especial no IX Encontro da Associação Brasileira de Ciência Política (ABCP) Brasília, 4-7 agosto 2014.

FERES JÚNIOR, João. Aprendendo com os erros dos outros. Revista de Sociologia e Política, n. 15, p.97-110.

FORJAZ, Maria Cecília Spina. (1997) A emergência da ciência política no Brasil: aspectos institucionais". Revista Brasileira de Ciências Sociais, 35, nov.

HARO, Fernando Ampudia de. O impacto de (não) ter impacto: Para uma sociologia crítica das publicações científicas. Revista Crítica de Ciências Sociais. Lisboa, n. 113, p. 83-106, 2017.

KEINERT, Fábio Cardoso; SILVA, Dimitri Pinheiro. A gênese da ciência política brasileira. Tempo social, $v$. 22, n. 1, p.79-98, 2010.

LAMOUNIER, Bolívar. (1982), A ciência política no Brasil: roteiro para um balanço crítico. In: (org.). Ciência política nos anos 80. Brasília: Editora da UnB.

LESSA, Renato. O campo da ciência política no Brasil: uma aproximação construtivista. In: MARTINS, Carlos Benedito (Org.) Horizontes das Ciências Sociais no Brasil - Ciência Política. São Paulo: ANPOCS, 2010, p. 13-50.

LEITE, Fernando Baptista. Posições e divisões na Ciência Política brasileira contemporânea: explicando sua produção acadêmica. Revista de Sociologia e Política, v. 18, n. 37, p.149-182, 2010.

LIMONGI, Fernando. Por uma sociologia das ciências sociais. In: (org.), História das ciências sociais no Brasil. 2 ed. São Paulo, Sumaré, 2001.

MILLS, Charles Wright. A imaginação sociológica. Rio de Janeiro: Zahar, 1965 [1959].

NASH, K. Contemporary Political Sociology. Oxford: Wiley-Blackwell Press, 2010.

ORUM, Anthony M. Introduction to political sociology. Upper Saddle River: Prentice Hall Press, 2001.

PERISSINOTTO, Renato; CODATO, Adriano. Opostos determinantes: a sociologia política brasileira no início do século XXI. In: MICELI, S.; MARTINS, Carlos B. (Orgs.) Sociologia brasileira II. São Paulo: Ateliê Editorial, 2018, p.19-64.

QUIRINO, Célia. Departamento de Ciência Política. Estudos Avançados USP, v.8, n. 22, p. 337-348, 1994.

REIS, Elisa Pereira. A construção intelectual e a política das ciências sociais brasileiras: a experiência do Iuperj. In: MICELI, Sergio (org.). A Fundação Ford no Brasil. São Paulo, Sumaré, 1993.

SALLUM JUNIOR, Brasilio. Notas sobre o surgimento da Sociologia Política em São Paulo. Política \& Sociedade, v. 1, n. 1, p. 73-86, 2002. 